\title{
Two Cases of Infective Endocarditis in Patients with Atopic Dermatitis
}

\author{
Bok Won Park, Yo Sup Shin, Eun Byul Cho, Eun Joo Park, Kwang Ho Kim, Kwang Joong Kim \\ Department of Dermatology, Hallym University Sacred Heart Hospital, College of Medicine, Hallym University, Anyang, Korea
}

Patients with atopic dermatitis have high rates of skin surface colonization of Staphylococcus aureus. At the same time, $S$. aureus is the major causative organism in infective endocarditis, approximately accounting for $30 \% \sim 50 \%$ cases of infective endocarditis. A 22-year-old male with severe atopic dermatitis presented with fever and myalgia. He was diagnosed with active infective endocarditis causing multiple cerebral infarction, splenic infarction, and septic shoulder requiring synovectomy. Blood culture proved methicillinsensitive Staphylococcus aureus bacteremia, and the culture from the skin revealed same bacteria. After treated with intravenous antibiotics for 6 weeks, patient was improved. Another 42-year-old female with severe atopic dermatitis who presented with fever and chilling was hospitalized due to acute infective endocarditis. She also had left flank pain and visual disturbance, due to splenic infarction and acute cerebral infarction, respectively. As blood culture revealed methicillin-sensitive Staphylococcus aureus bacteremia, she treated with intravenous antibiotics for 6 weeks. The route of entry of two patients was attributed to the patient eczematous scratching lesion of poorly controlled atopic dermatitis. Infective endocarditis can result in the context of acute deterioration of atopic dermatitis. Dermatologists need to pay attention to this risk and actively manage such conditions in or-

Received September 29, 2017, Revised December 13, 2017, Accepted for publication December 31, 2017

Corresponding author: Kwang Ho Kim, Department of Dermatology, Hallym University Sacred Heart Hospital, 22 Gwanpyeong-ro 170beon-gil, Dongangu, Anyang 14068, Korea. Tel: 82-31-380-3765, Fax: 82-31-386-3761, E-mail: dermakkh@naver.com ORCID: https://orcid.org/0000-0001-5315-6031

This is an Open Access article distributed under the terms of the Creative Commons Attribution Non-Commercial License (http://creativecommons. org/licenses/by-nc/4.0) which permits unrestricted non-commercial use, distribution, and reproduction in any medium, provided the original work is properly cited.

Copyright (c) The Korean Dermatological Association and The Korean Society for Investigative Dermatology der to decrease the risk of infective endocarditis arising from skin lesions in atopic patients. For these reasons, we herein report two cases of infective endocarditis in patients with atopic dermatitis. (Ann Dermatol 31(1) 70 74, 2019)

\section{-Keywords-}

Atopic dermatitis, Infective or Infectious endocarditis, Staphylococcus aureus

\section{INTRODUCTION}

Patients with atopic dermatitis have high rates of skin surface colonization of Staphylococcus aureus ${ }^{1-3}$. At the same time, $S$. aureus is the major causative organism in infective endocarditis, approximately accounting for $30 \% \sim 50 \%$ cases of infective endocarditis ${ }^{4}$. Atopic dermatitis is a relatively common disease and its prevalence is increasing in Korea $^{5,6}$. In atopic dermatitis, itching and scratching are common symptoms, resulting in infiltration of Staphylococcus aureus, which is frequently colonized in patients with atopic dermatitis due to weak skin barrier function $^{7}$. There have been few reports of cases of infective endocarditis occurring in patients with atopic dermatitis considering the high prevalence of atopic dermatitis, thereby few studies have been conducted on the association between them. Given that atopic dermatitis is a common condition and infective endocarditis is a life-threatening disease, it is quite surprising that dermatologists have had little interest in this relationship.

\section{CASE REPORT}

\section{Case 1}

A 22-year-old man presented to the emergency department with fever and generalized skin rash. He also com- 
plained of chest pain, bilateral visual disturbance, and abdominal pain. There was no previous history of heart disease, rheumatic fever, or dental procedure, and no specific familial history of heart disease or dermatologic disease. He had uncontrolled severe atopic dermatitis, and have been treated with prednisolone started with $20 \mathrm{mg} /$ day for several weeks and changed to cyclosporine $200 \mathrm{mg} /$ day for 6 months. He had extremely dry skin with lichenification with oozing on whole body, especially on upper extremities. He was transferred to division of infectious disease.

On physical examination, the body temperature was $39.1^{\circ} \mathrm{C}$, pulse rate $120 / \mathrm{min}$ and blood pressure $100 / 50$ $\mathrm{mmHg}$. Osler nodes and splinter hemorrhage were observed on his hands (Fig. 1). Laboratory investigation revealed hemoglobin $16.4 \mathrm{~g} / \mathrm{d}$, white blood cell (WBC) $15,400 / \mu \mathrm{l}$ with $84.4 \%$ neutrophil count, platelets $299,000 / \mu \mathrm{l}$, erythrocyte sedimentation rate (ESR) 51 $\mathrm{mm} / \mathrm{hr}$, C-reactive protein $358.53 \mathrm{mg} / \mathrm{L}$, and total immunoglobulins E (IgE) $609 \mathrm{IU} / \mathrm{ml}$. Urine analysis showed no demonstrable results, and chest X-ray was normal. 12 lead electrocardiogram (EKG) showed sinus tachycardia with features of left ventricular hypertrophy. Transthoracic echocardiogram showed $1.7 \times 0.6 \mathrm{~cm}$ sized mitral valve vegetation (Fig. 2), with normal ejection fraction. Computed tomography $(\mathrm{CT})$ scan of the brain was normal but magnetic resonance imaging (MRI) scan identified multiple cerebral infarction due to embolism. CT scan of the abdomen was performed due to abdominal pain, showing splenic infraction due to embolism. Shoulder pain devel-

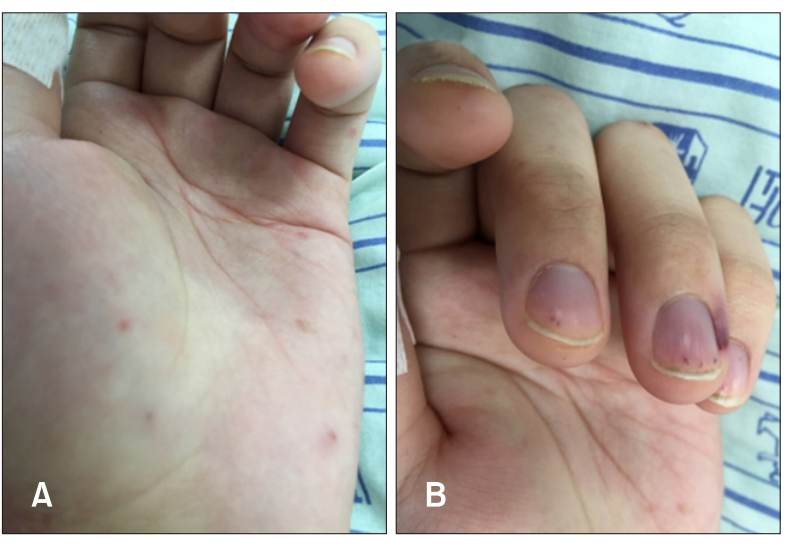

Fig. 1. Osler nodes, Janeway lesions, and splinter hemorrhages are observed on the hands on the patient 1 . We received the patient's consent form about publishing all photographic materials.
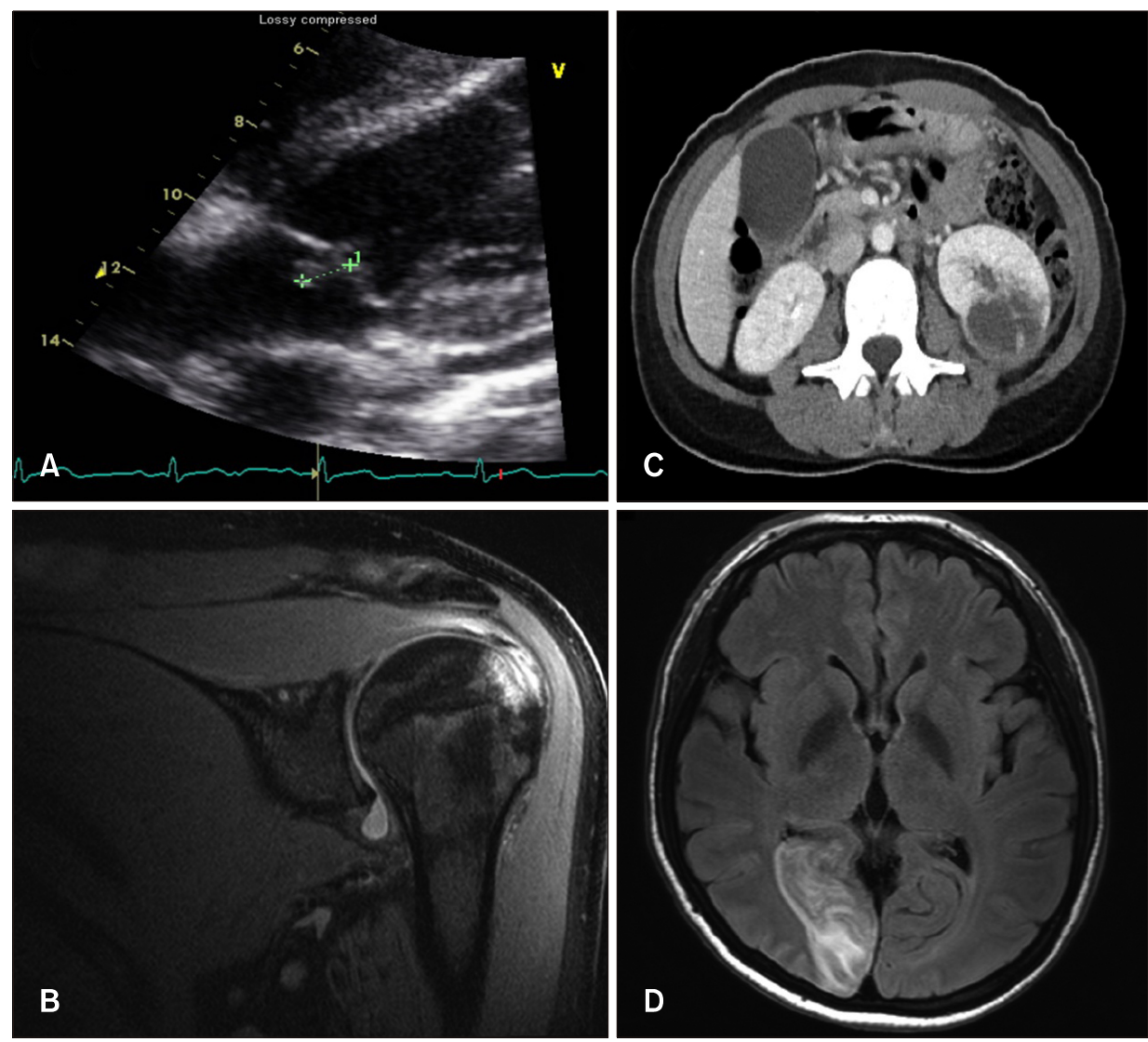

Fig. 2. (A) Echocardiography of the patient 1 . It showed $1.7 \times 0.6 \mathrm{~cm}$ sized hypermobile echogenic material attatched to mitral valve, which indicates intracardiac vegetation. (B) Magnetic resonance imaging (MRI) scan of the shoulder of the patient 1 . It revealed septic arthritis which requires surgical intervention. (C) Computed tomography scan of the abdomen of the patient 2. It indicates acute pyelonephritis of the left kidney. (D) MRI scan of the brain of the patient 2 . Multiple cerebral infraction attributed to embolism can be observed. 
oped, and MRI scan showed septic arthritis (Fig. 2). Patient was referred to orthopedics and received synovectomy surgery. Two sets of blood cultures grew methicillin-sensitive $S$. aureus and the culture from the skin grew $S$. aureus with same antimicrobial susceptibilities. The patient was commenced on intravenous nafcillin $0.5 \mathrm{~g} / 6$ hour and changed to vancomycin $1 \mathrm{~g} / 12$ hour due to side effect of nafcillin. After 6 weeks of intravenous antibiotics treatment, his condition improved and discharged.

\section{Case 2}

A 42-year-old woman with atopic dermatitis presented to the emergency department with fever and skin rash. She was suffered from left flank pain and visual disturbance. There was no previous history of heart disease, rheumatic fever, or dental procedure, and no familial history of heart disease or dermatologic disease. She had lichenified skin lesion with oozing on trunk, but she have not been treated with her atopic dermatitis except application of moisturizer.

On examination, the body temperature was $38.6^{\circ} \mathrm{C}$, pulse rate $83 / \mathrm{min}$ and blood pressure $110 / 70 \mathrm{mmHg}$. Laboratory investigation revealed hemoglobin $7.7 \mathrm{~g} / \mathrm{d}$, WBC 10,700/ $\mu$ I with $78.5 \%$ neutrophil count, platelets $378,000 / \mu \mathrm{l}$, ESR $26.4 \mathrm{~mm} / \mathrm{hr}$, C-reactive protein $115.80 \mathrm{mg} / \mathrm{L}$, and total $\operatorname{lgE}>2,500 \mathrm{IU} / \mathrm{mL}$. Urine analysis showed no demonstrable results, and chest X-ray was normal. 12 lead EKG showed no demonstrable finding. Transthoracic echocardiogram revealed hypermobile $0.6 \times 0.8 \mathrm{~cm}$ sized mi- tral valve vegetation, with normal ejection fraction. MRI scan of the brain identified multiple cerebral infarction due to embolism (Fig. 1). CT scan of the abdomen showed acute pyelonephritis on left kidney and splenic infraction due to embolism (Fig. 2). Two sets of blood cultures grew methicillin-sensitive Staphylococcus aureus. The patient was treated with intravenous nafcillin $1 \mathrm{~g} / 4$ hour. After 6 weeks of intravenous antibiotics treatment, her condition improved and discharged.

\section{DISCUSSION}

S. aureus is one of the major strains responsible for $30 \%$ $50 \%$ of infective endocarditis, emerging as one of the most common causes of infective endocarditis ${ }^{4}$. Skin colonization of $S$. aureus is also common in patient with atopic dermatitis ${ }^{1-3}$. S. aureus may cause superficial skin infection in patient with atopic dermatitis, but it may also cause invasive systemic infection, and bacteremia caused by $S$. aureus may cause severe conditions such as infective endocarditis and septic arthritis ${ }^{8}$. Valve destruction or neurological complications are more common, especially when $S$. aureus is the causative organism of bacteremia ${ }^{9}$.

Although studies on the relevance of infective endocarditis and atopic dermatitis have been reported steadily in several case reports, there is very little controlled research on relevance. Several case reports are described in Table $1^{10-17}$. In one study ${ }^{18}$, it was found that $6.7 \%(8 / 120)$ of patients with infective endocarditis had previous history of

Table 1. Case reports of patients with atopic dermatitis and infective endocarditis

\begin{tabular}{|c|c|c|c|c|c|}
\hline Case & Author & $\begin{array}{l}\text { Age }(y) \\
\text { /gender }\end{array}$ & Underlying disease & Blood culture & Complication \\
\hline 1 & Yamamoto et al. ${ }^{10}$ & $27 / M$ & Atopic dermatitis & MSSA & Mitral valve impairment \\
\hline 2 & Grabczynska et al. ${ }^{11}$ & $24 / \mathrm{M}$ & $\begin{array}{l}\text { Atopic dermatitis, cerebral palsy, asthma, } \\
\text { deafness, previeous episodes of IE }\end{array}$ & MSSA & $(-)$ \\
\hline 3 & Pike et al. ${ }^{12}$ & $3 / \mathrm{M}$ & $\begin{array}{l}\text { Atopic dermatitis, Ventricular septal defect, } \\
\text { congenital immunodeficiency }\end{array}$ & $\begin{array}{l}\text { Staphylococcus } \\
\text { aureus }\end{array}$ & Tricuspid valve impairment \\
\hline 4 & Satchell et al. ${ }^{13}$ & $50 / F$ & Atopic dermatitis, asthma, allergic rhinitis & S. aureus & Mitral valve impairment \\
\hline 5 & Beneson et al. $^{14}$ & $36 / F$ & Atopic dermatitis & MSSA & Mitral valve impairment \\
\hline 6 & Beneson et al. ${ }^{14}$ & $17 / M$ & Atopic dermatitis & MSSA & Septic arthritis of right shoulder \\
\hline 7 & Mohiyiddeen et al. ${ }^{15}$ & $30 / \mathrm{M}$ & Atopic dermatitis, asthma & MSSA & Mitral valve impairment \\
\hline 8 & Micallef et al. ${ }^{16}$ & $39 / \mathrm{M}$ & Atopic dermatitis, anxiety disorder & MSSA & $\begin{array}{l}\text { Bacterial meningitis and mitral } \\
\text { regurgitation }\end{array}$ \\
\hline 9 & Horimoto et al. ${ }^{17}$ & $34 / F$ & Atopic dermatitis & MSSA & $\begin{array}{l}\text { Tricuspid valve impairement, } \\
\text { multiple septic pulmonary } \\
\text { emboli, and heart failure }\end{array}$ \\
\hline 10 & Present case 1 & $22 / \mathrm{M}$ & Atopic dermatitis & MSSA & $\begin{array}{l}\text { Cerebral infarction, splenic } \\
\text { infarction, septic arthritis }\end{array}$ \\
\hline 11 & Present case 2 & $42 / F$ & Atopic dermatitis & MSSA & $\begin{array}{l}\text { Cerebral infarction, acute } \\
\text { pyelonephritis, splenic infarction }\end{array}$ \\
\hline
\end{tabular}

M: male, F: female, IE: infective endocarditis, MSSA: methicillin-sensitive Staphylococcus aureus. 
atopic dermatitis. Among patients with infective endocarditis, the age at onset was lower in patients with atopic dermatitis. Moreover, those with atopic dermatitis as the underlying disease were significantly more like to have Methicillin sensitive $S$. aureus as the causative organism of endocarditis.

In contrast to the skin colonization in the general population, the higher colonization of $S$. aureus in patient with atopic dermatitis can be explained for several reasons. In atopic dermatitis, skin barrier function is impaired, making penetration of bacteria more easily to penetration ${ }^{7}$. Furthermore, in patients with atopic dermatitis, cathelicidin (LL-37) and beta-defensin2 (HBD-2), known as inflammation-induced antimicrobial, antifungal, and antiviral peptides, are reduced ${ }^{19}$. It may play a role in enhancing susceptibility to colonization of $S$. aureus. For these reasons, the risk of $S$. aureus infection increases in patient with atopic dermatitis.

Both of the patients in this report developed infective endocarditis in the absence of underlying disease, such as other specific heart disease, or dental treatment. In the first case, atopic dermatitis was severe and uncontrollable at the onset of infective endocarditis, and the patient was being treated with drugs including cyclosporine and methylprednisolone for atopic dermatitis. The use of these immunomodulators could be another risk factor for infective endocarditis, but the second case was an atopic patient who did not manage without special treatment. These cases with no specific underlying disease in these patients with uncontrolled atopic dermatitis may be able to reinforce the association between atopic dermatitis and infective endocarditis.

As in the case, infective endocarditis due to $S$. aureus is a serious condition that can cause serious side effects such as cerebral embolism, multiorgan embolism, and septic shoulder. In addition to cardiovascular complication, pulmonary complications such as pneumonia and ocular complications have also been reported in infective endocarditis of atopic dermatitis patients ${ }^{8}$. Considering the high prevalence of atopic dermatitis and the severity of infective endocarditis, strict control of atopic dermatitis is necessary. Active management of eczematous lesions and impaired skin barrier is needed, and topical or systemic antibiotics might be helpful for acute flare for a short time. In addition, immunosuppressants are frequently used in treating atopic dermatitis. Patients with severe skin lesions with immunosuppressants therapy may need further close-screening.

In conclusion, it should be recognized that atopic dermatitis is a potential risk factor for infective endocarditis, and further research is needed to evaluate and manage these risks.

\section{CONFLICTS OF INTEREST}

The authors have nothing to disclose.

\section{ORCID}

Bok Won Park, https://orcid.org/0000-0002-7508-8428

Yo Sup Shin, https://orcid.org/0000-0001-5100-2450

Eun Byul Cho, https://orcid.org/0000-0001-5603-5112

Eun Joo Park, https://orcid.org/0000-0002-9924-515X

Kwang Ho Kim, https://orcid.org/0000-0001-5315-6031

Kwang Joong Kim, https://orcid.org/0000-0003-4158-6100

\section{REFERENCES}

1. Boguniewicz M, Leung DY. Atopic dermatitis: a disease of altered skin barrier and immune dysregulation. Immunol Rev 2011;242:233-246.

2. Boguniewicz M, Leung DY. Recent insights into atopic dermatitis and implications for management of infectious complications. J Allergy Clin Immunol 2010;125:4-13.

3. Hauser C, Wuethrich B, Matter L, Wilhelm JA, Sonnabend W, Schopfer K. Staphylococcus aureus skin colonization in atopic dermatitis patients. Dermatologica 1985;170:35-39.

4. Mylonakis E, Calderwood SB. Infective endocarditis in adults. N Engl J Med 2001;345:1318-1330.

5. Kangmo A. The prevalence of atopic dermatitis in Korean children. Allergy Asthma Immunol Res 2016;8:1-2.

6. Lee JH, Han KD, Kim KM, Park YG, Lee JY, Park YM. Prevalence of atopic dermatitis in Korean children based on data from the 2008-2011 Korean National Health and Nutrition Examination Survey. Allergy Asthma Immunol Res 2016;8:79-83.

7. Aly R, Maibach HI, Shinefield HR. Microbial flora of atopic dermatitis. Arch Dermatol 1977;113:780-782.

8. Patel D, Jahnke MN. Serious complications from Staphylococcal aureus in atopic dermatitis. Pediatr Dermatol 2015; 32:792-796.

9. Harada M, Nishi Y, Tamura S, Iba Y, Abe K, Yanbe Y, et al. [Infective endocarditis with a huge mitral vegetation related to atopic dermatitis and high serum level of infectionrelated antiphospholipid antibody: a case report]. J Cardiol 2003;42:135-140. Japanese.

10. Yamamoto T, Yodogawa K, Wakita S, Ogano M, Tokita M, Miyagi $Y$, et al. Recurrent prosthetic valve endocarditis caused by Staphylococcus aureus colonizing skin lesions in severe atopic dermatitis. Intern Med 2007;46:571-573.

11. Grabczynska SA, Cerio R. Infective endocarditis associated with atopic eczema. Br J Dermatol 1999;140:1193-1194.

12. Pike MG, Warner JO. Atopic dermatitis complicated by acute bacterial endocarditis. Acta Paediatr Scand 1989;78: 463-464.

13. Satchell AC, Barnetson RS. Staphylococcal septicaemia 
complicating treatment of atopic dermatitis with mycophenolate. Br J Dermatol 2000;143:202-203.

14. Beneson S, Zimhony O, Dahan D, Solomon M, Raveh D, Schlesinger $\mathrm{Y}$, et al. Atopic dermatitis-a risk factor for invasive Staphylococcus aureus infections: two cases and review. Am J Med 2005;118:1048-1051.

15. Mohiyiddeen G, Brett I, Jude E. Infective endocarditis caused by Staphylococcus aureus in a patient with atopic dermatitis: a case report. J Med Case Rep 2008;2:143.

16. Micallef MJ, Ramphul A. Infective endocarditis in a patient with atopic dermatitis. J Cardiol Cases 2016;13:153-154.
17. Horimoto K, Kubo T, Matsusaka H, Baba H, Umesue M. Right-sided infective endocarditis with a ruptured sinus of Valsalva and multiple septic pulmonary emboli in a patient with atopic dermatitis. Intern Med 2015;54:797-800.

18. Fukunaga N, Okada Y, Konishi Y, Murashita T, Koyama T. Pay attention to valvular disease in the presence of atopic dermatitis. Circ J 2013;77:1862-1866.

19. Ong PY, Ohtake T, Brandt C, Strickland I, Boguniewicz M, Ganz T, et al. Endogenous antimicrobial peptides and skin infections in atopic dermatitis. N Engl J Med 2002;347: 1151-1160. 